\title{
INJECTOR CHARACTERIZATION FOR A GASEOUS OXYGEN-METHANE SINGLE ELEMENT COMBUSTION CHAMBER
}

\author{
M.P. Celano ${ }^{1}$, S. Silvestri ${ }^{1}$, G. Schlieben ${ }^{1}$, \\ C. Kirchberger ${ }^{1}$, O. J. Haidn ${ }^{1}$, and O. Knab ${ }^{2}$ \\ ${ }^{1}$ Technische Universität München (TUM) \\ Institute for Flight Propulsion (LFA) \\ 15 Boltzmannstr., Garching, Munich 85747, Germany \\ ${ }^{2}$ Airbus Defense and Space \\ Ottobrunn, Germany
}

The results from an experimental investigation on an oxygen-methane single-injector combustion chamber are presented. They provide detailed information about the thermal loads at the hot inner walls of the combustion chamber at representative rocket engine conditions and pressures up to 20 bar. The present study aims to contribute to the understanding of the thermal transfer processes and to validate the in-house design tool Thermtest and a base for an attempt to simulate the flame behavior with large-eddy simulation (LES). Due to the complex flow phenomena linked to the use of cryogenic propellants, like extreme variation of flow properties and steep temperature gradients, in combination with intensive chemical reactions, the problem has been partially simplified by injecting gaseous oxygen $(\mathrm{GOx})$ and gaseous methane $\left(\mathrm{GCH}_{4}\right)$.

\section{NOMENCLATURE}

a inner combustion chamber width/height, $\mathrm{m}$

$A_{\mathrm{cc}}$ combustion chamber cross section, $\mathrm{m}^{2}$

$A_{\mathrm{hw}}$ hot wall area, $\mathrm{m}^{2}$

$A_{\text {th }}$ throat cross section, $\mathrm{m}^{2}$

$b \quad$ external combustion chamber width, $\mathrm{m}$

$c \quad$ specific heat capacity, $\mathrm{J} /(\mathrm{kg} \cdot \mathrm{K})$

$C_{d}$ discharge coefficient

$D_{i} \quad$ inner diameter, $\mathrm{m}$

$D_{o} \quad$ outer diameter, $\mathrm{m}$

$\dot{E}_{\text {in }} \quad$ total energy entering the control volume, W

$\dot{E}_{\text {out }}$ total energy leaving the control volume, W 


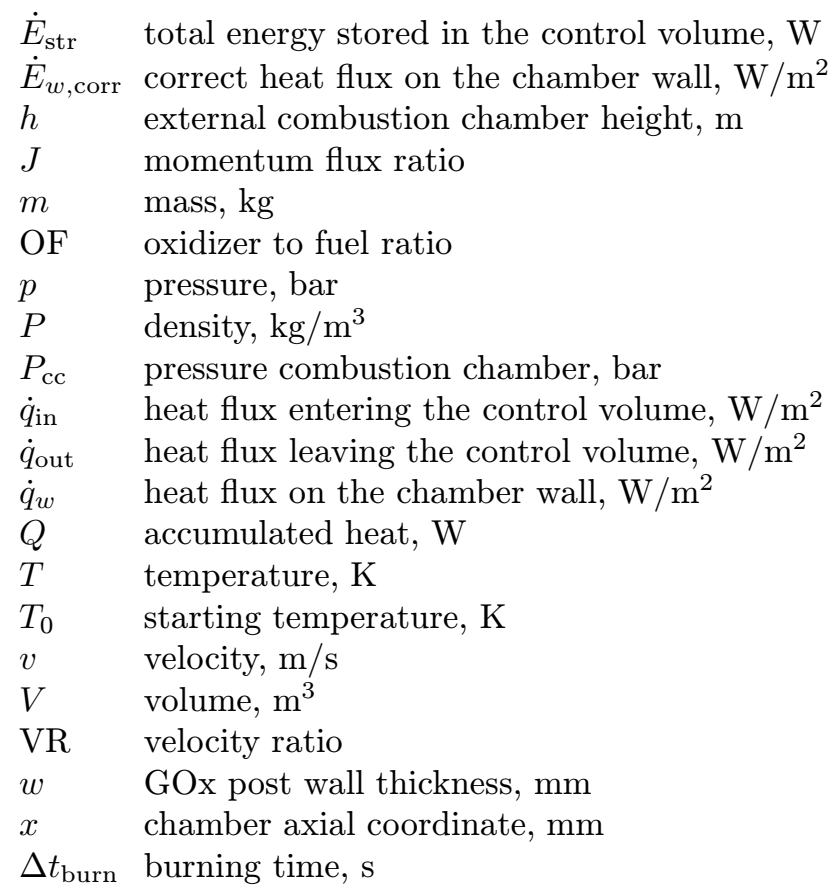

\section{INTRODUCTION}

Today's high performance liquid propellant rocket engines for transfer into orbit and space exploration are mostly based on well-established cryogenic propellant combinations like liquid oxygen / liquid hydrogen $\left(\mathrm{LOx} / \mathrm{LH}_{2}\right)$, due to their high specific impulse, or classical storable propellants like MMH/NTO (monomethylhydrazine/ nitrogen tetroxide) due to the hypergolic nature. The demanding issues in terms of high operational and handling costs of such propellants increased the attention for hydrocarbons in the predevelopment of future launch vehicles [1]. Liquid oxygen / hydrocarbons rocket engines have the advantage in fact of being relatively low cost, low pollution, and high performance.

Many kinds of LOx/kerosene rocket engines, such as H-1, F-1, RD-170, RD180, were developed and manufactured successfully in the USA and the former Soviet Union. Instead, LOx/methane propellant combination has a critical gap in knowledge of detailed heat transfer characteristics and injector technology and even if considered for rocket application at various times in the U.S. Space program [2] and in Russia [3], LOx/methane engines are not flying yet.

Key parameters for the selection of hydrocarbons fuels are their cooling properties. In this context, oxygen/methane is one of the most promising propellant combinations. In particular, for the use in cooling systems, the threshold value of 
coolant-side wall temperatures is limited by coking considerations. For methane the widely quoted value is $970 \mathrm{~K}$, higher than propane $(700 \mathrm{~K})$ and kerosene $(590 \mathrm{~K})[4]$. Moreover, the heat transfer performance of methane is higher compared to other hydrocarbon fuels as a result of its high thermal conductivity, specific heat, and low viscosity. In general, methane shows, compared to other potential candidates, better overall performance from a system point of view [5], higher specific impulse [6], no risks for human health, simple extractability from natural gases, and a density 6 times higher than hydrogen when stored in liquid state at typical tank pressures.

Although several research groups have performed fundamental experimental and numerical investigations $[7,8]$, only a limited amount of experimental data is available for oxygen/methane combustion at relevant combustion chamber conditions. High temperature differences between the hot combustor gases and the cooling fluid in combination with high heat transfer coefficients yield extreme heat flux levels to the combustion chamber walls. For optimal cooling design, the precise knowledge of the heat transfer processes in rocket engines is mandatory. The importance of these data is confirmed by the fact that life cycle prediction of rocket engine strongly depends on the accuracy of wall temperature predictions, where an error of $40 \mathrm{~K}$ may lead to 50 percent life reduction in a cryogenic propellant rocket chamber [9]. In particular, the technology of propellant injection is central for optimal rocket combustor performance due to its effect on propellant preparation and thermal loads to the walls.

In the context of the national research program Transregio SFB/TR-40 on "Technological Foundation for the design of thermally and mechanically high loaded components of Future Space Transportation System," two multiinjector combustion chambers have been designed for $\mathrm{GOx}$ and $\mathrm{GCH}_{4}$, respectively, focusing on high pressure (up to 100 bar) and film cooling behavior and low pressure (up to 40 bar) application for optical measurement techniques. One of the key aspects of this project is to improve the knowledge on heat transfer processes and cooling methods at representative conditions, in particular, focusing on injector-injector and injector-wall interactions. Given these justifications, the effort has been initiated to experimentally document the detailed wall heat flux characteristic of a $\mathrm{GOx} / \mathrm{GCH}_{4}$ shear coaxial single-element injector over a range of pressures and mixture ratios. Additionally, the wall heat flux results were used as a test case for the validation of the in-house engineering tool Thermtest [10] and to determine the feasibility of LES as a tool at the Georgia Institute of Technology for the analysis of the flame structure and flow features [11].

\section{TEST SPECIMEN AND EXPERIMENTAL SETUP}

The investigations presented are performed at the newly built institute's test facility for $\mathrm{GCH}_{4}$ and $\mathrm{GOx}$, designed for interface pressures up to 50 bar. 
In this section a description of the instrumented subscale rocket chamber, injector geometry, flow conditions, and data analysis procedures, which are used for the wall heat flux characterization experiments, is presented.

\subsection{Thrust Chamber and Injector Element}

The present test campaign is performed using a modular combustion chamber with a square cross section designed for a testing time of up to $4 \mathrm{~s}$ at a chamber pressure of 20 bar and mixture ratio of 3.4. The inner chamber dimensions are shown in Table 1.

Table 1 Combustion chamber dimensions

\begin{tabular}{ccccc}
\hline $\begin{array}{c}\text { Chamber } \\
\text { length, } \\
\mathrm{mm}\end{array}$ & $\begin{array}{c}\text { Chamber } \\
\text { width, } \\
\mathrm{mm}\end{array}$ & $\begin{array}{c}\text { Chamber } \\
\text { height, } \\
\mathrm{mm}\end{array}$ & $\begin{array}{c}\text { Throat } \\
\text { height, } \\
\mathrm{mm}\end{array}$ & $\begin{array}{c}\text { Contraction } \\
\text { ratio } A_{\mathrm{cc}} / A_{\mathrm{th}}\end{array}$ \\
\hline 290 & 12 & 12 & 4.8 & 2.5 \\
\hline
\end{tabular}

The single-element rocket combustion chamber, depicted in Fig. 1, consists of two chamber segments of 174 and $145 \mathrm{~mm}$ and a nozzle segment of 20 -millimeter length. The nozzle differs from a usual configuration due to its throat with a rectangular cross section of $4.8 \times 12 \mathrm{~mm}$, which results in a contraction ratio of 2.5 and Mach number in the chamber of 0.24 . The thrust generated at the design point conditions is up to $200 \mathrm{~N}$. The material used for the chamber segments and the nozzle segment is oxygen-free copper $(\mathrm{Cu}-\mathrm{HCP}$ - high conductivity phosphorous copper).

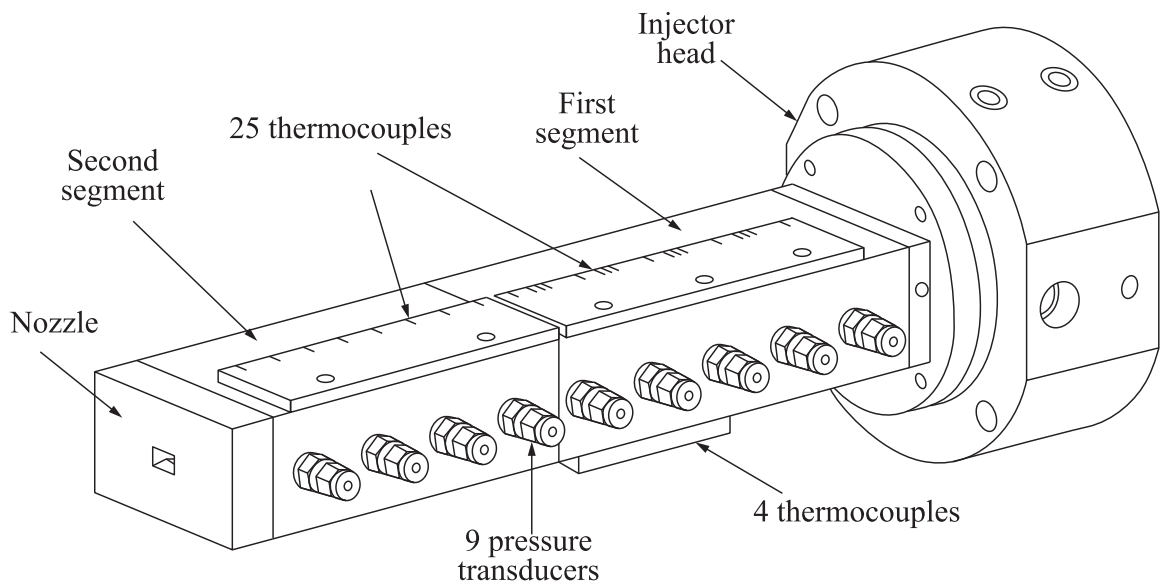

Figure 1 Combustion chamber with square cross section 


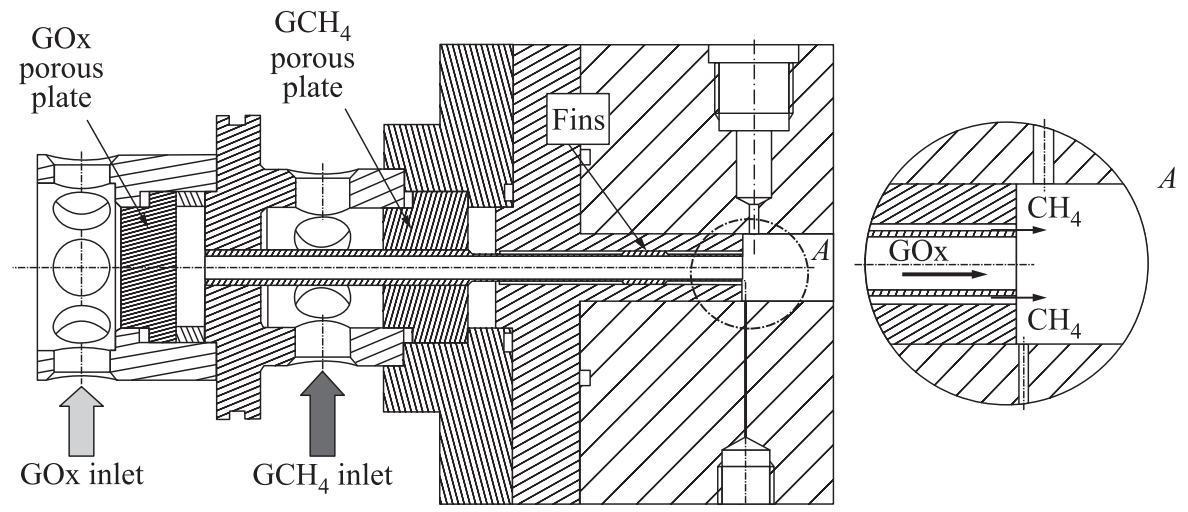

Figure 2 Single shear coaxial injector element

The injector head of the combustor is designed to allow different injector designs. For the current study, a single shear coaxial injector element is integrated as shown in Fig. 2. To ensure homogeneous injection conditions, in terms of temperature and pressure, two porous plates are placed in the oxidizer and fuel manifolds, respectively.

The chamber sections are held together by four tie rods having spiral springs to assure constant clamping force during thermal expansion of the chamber. The modular setup simplifies changes in chamber length or hardware configurations. Furthermore, the entire assembly is capacitive cooled in order to keep the design flexible and more accessible for temperature measurements.

Previous experimental results [2] showed that configurations with the GOx post recessed have higher heat flux at the near injection-face region than GOx post flush counterparts. This indicates that the mixing cup, provided by recessing the GOx post, has a positive effect in the mixing and combustion characteristics of a shear coaxial injector. Nevertheless, for simplicity, this study omits these advancements and the GOx post is configured flush with respect to the injection face. Table 2 shows the main injector characteristic dimensions.

In order to be able to center the injector element in the faceplate, it has been equipped with four equally-spaced fins. For the current test series, the fins are

Table 2 Injector dimensions

\begin{tabular}{ccccc}
\hline $\begin{array}{c}\text { GOx } \\
\text { diameter } D_{i}, \\
\mathrm{~mm}\end{array}$ & $\begin{array}{c}\text { GOx } \\
\text { post wall } \\
\text { thickness } w, \\
\mathrm{~mm}\end{array}$ & $\begin{array}{c}\text { GOx } \\
\text { post recess, } \\
\mathrm{mm}\end{array}$ & $\begin{array}{c}\mathrm{GCH}_{4} \\
\text { diameter } D_{0}, \\
\mathrm{~mm}\end{array}$ & $\begin{array}{c}\text { Injector } \\
\text { area ratio } \\
A_{\mathrm{CH}_{4}} / A_{\mathrm{GOx}}\end{array}$ \\
\hline 4 & 0.5 & 0 & 6 & 0.7 \\
\hline
\end{tabular}


positioned with an angle of $45^{\circ}$ to the combustion chamber center plane. The oxidizer is injected through an inner tube at velocities of about $122 \mathrm{~m} / \mathrm{s}$ and the fuel through the annular gap at velocities of $132 \mathrm{~m} / \mathrm{s}$, for $20 \mathrm{bar}$, OF of 2.6 operating conditions. Shear forces between the propellants determine the mixing efficiency. Therefore, nondimensional numbers such as the velocity ratio VR and the momentum flux ratio $J$ are employed to characterize injection conditions:

$$
\mathrm{VR}=\frac{v_{\mathrm{GCH}_{4}}}{v_{\mathrm{GOx}}} ; \quad J=\frac{\left(\rho v^{2}\right)_{\mathrm{GCH}_{4}}}{\left(\rho v^{2}\right)_{\mathrm{GOx}}} .
$$

The values of the velocity ratio (VR) and the momentum flux ratio $(J)$ range from 0.89 to 1.1 and from 0.38 to 0.62 , respectively. Both the velocity ratio and the momentum flux ratio are based on propellant temperatures and pressure at injection conditions.

\subsection{Experimental Setup}

The experimental setup is equipped with standard instrumentations required to characterize the operation of the chamber. For a better understanding of the complex heat transport processes, equally spaced pressure transducers on the side wall provide for a well resolved measurement of the wall pressure distribution $p(x)$ along the chamber axis. A schematic of the combustion chamber and the associated sensor locations is given in Fig. 1. WIKA A10 pressure transducers are used to record the axial evolution of the static chamber wall pressure (PC0...PC8). The pressure sensors are individually calibrated and operated at a data acquisition rate of $100 \mathrm{~Hz}$.

To characterize the injection conditions, thermocouples of Type K, with 0.5millimeter diameter, and pressure transducers are installed in the chamber manifolds, prior the porous plates. To determine the temperature field in the chamber, thermocouples are applied in the chamber walls in three different ways: type $\mathrm{T}$ thermocouples of 0.5 -millimeter diameter located within the chamber wall with 1-, 2-, and 3-millimeter distance to the hot wall, additionally two coaxial Type $\mathrm{T}$ thermocouples (Medtherm), flush mounted with the hot wall, and five Type $\mathrm{K}$ surface thermocouples attached to the external surface. The Type $\mathrm{T}$ thermocouples and the surface thermocouples are mounted with a regular path of $17 \mathrm{~mm}$ in the upper surface of the first and second segments, along the center plane of the combustion chamber. Instead, the Medtherm thermocouples are press-fitted into the chamber wall, in corresponding axial positions in the lower surface of the first segment. In order to ensure better contact, the tip is polished to match the flat surface of the chamber. The thermocouple location pattern is shown in Fig. 3.

The thermocouples are inserted in precisely manufactured cylindrical holes and are kept in positions by a spring loaded system. The spring loading of the 


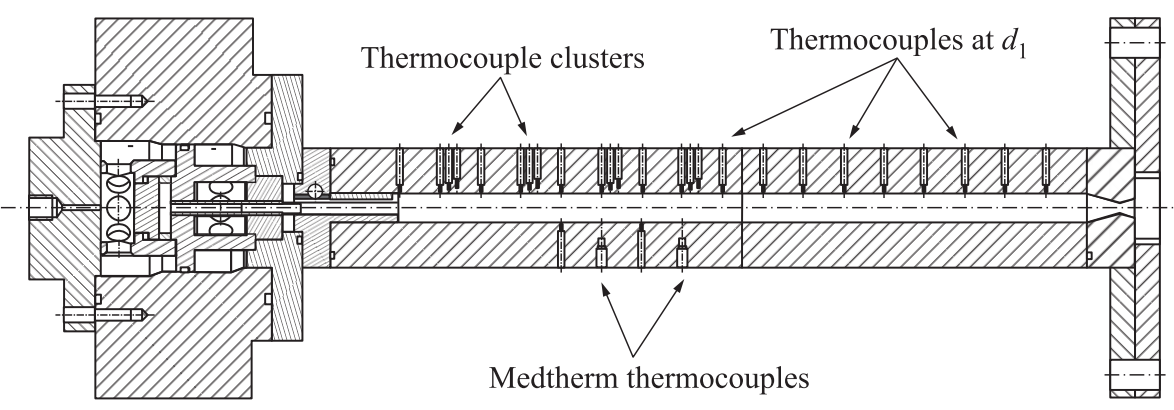

Figure 3 Thermocouple position along the combustion chamber axis

Table 3 Thermocouple positions

\begin{tabular}{cc}
\hline $\begin{array}{c}\text { Thermocouple } \\
\text { radial } \\
\text { position }\end{array}$ & $\begin{array}{c}\text { Distance } \\
\text { from the hot } \\
\text { gas side, mm }\end{array}$ \\
\hline$d_{1}$ & 1 \\
$d_{2}$ & 2 \\
$d_{3}$ & 3 \\
\hline
\end{tabular}

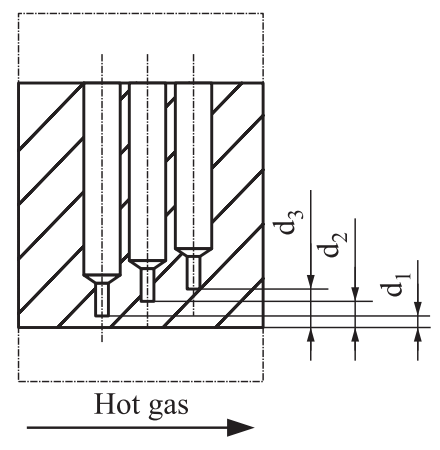

Figure 4 Thermocouple positions in the chamber wall

thermocouples provides a constant force of about $2 \mathrm{~N}$, which ensures a continuous contact between the thermocouples tip and the base of the hole. This setup aims to minimize the chance of potential loss of contact as the material undergoes expansion and contraction due to changes in temperature or vibrations during the hot run [12]. Moreover, in order to be able to reconstruct the temperature field in the chamber material, thermocouples are placed at different distances from the hot gas wall (Table 3). Four clusters of three wall thermocouples each at a different distance $d\left(d_{1}, d_{2}\right.$, and $\left.d_{3}\right)$ from the hot-wall are located with a constant pitch in axial direction, as depicted in Fig. 4.

\subsection{Operating Conditions}

The ignition of the chamber is achieved by a torch igniter using $\mathrm{GCH}_{4} / \mathrm{GOx}$, mounted to the side wall of the combustion chamber in the region near the faceplate. The mass flow rates in the combustion chamber $\left(\mathrm{GCH}_{4}, \mathrm{GOx}\right.$, and gaseous nitrogen $\left(\mathrm{GN}_{2}\right)$ for the purge) are set by sonic orifices in the feed lines 
and the upstream pressure. The orifices in the feed lines to the main injector are manufactured with appropriate diameters and calibrated with nitrogen using a Coriolis flowmeter prior to the test campaign. For the design of the operating points, the characteristic velocity $c^{*}$ is calculated with CEA2 [13] and a combustion efficiency of $\eta_{c^{*}}=1$ is assumed. Since the pressure values upstream the orifice are influenced by the mass flow rates, flow checks are required in order to accurately set the pressure regulators. The actual mass flows are calculated from the recorded pressure, temperature signals, and the orifice calibration data after the test. The test matrix includes testing at pressure levels from nominally

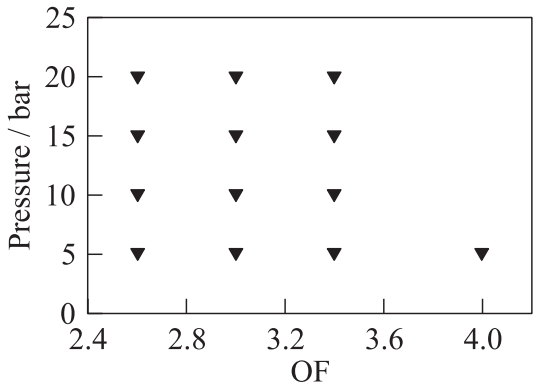

Figure 5 Test envelope - operating points

20 bar down to 5 bar and at mixture ratios of $2.6,3.0,3.4$, and 4 (4 only for the 5-bar case). For the OF conditions, both the $\mathrm{GCH}_{4}$ and $\mathrm{GOx}$ mass flow rates are scaled accordingly with pressure. Figure 5 gives an overview of the planned operating points.

To operate the combustion chamber, a test sequence is programmed into the control system. The sequence is divided into three main periods: ignition, main combustion chamber operation, and shutdown. Purge flows of nitrogen $\left(\mathrm{GN}_{2}\right)$ are activated before and after the main propellant valves are opened. To minimize the influence of the igniter on the temperature measurement, the igniter runs at minimum power for only $600 \mathrm{~ms}$ ( $200 \mathrm{~ms}$ prior to the opening of the main valves). The burn times of the combustion chamber are chosen to reach stable operation, required for the thermal load measurements. While the tests at 10, 15, and 20 bar are run for $3 \mathrm{~s}$, the burn time for the 5 -bar tests are increased to $4 \mathrm{~s}$, due to the lower heat loads. Each of the operating points is run at least two times to ensure the repeatability of the recorded test data. Good agreement is obtained for all load points.

\section{EXPERIMENTAL RESULTS AND DISCUSSION}

The main goal of this investigation is to determine the thermal and pressure load distributions along the combustion chamber main axis in order to be able to characterize the injector element behavior. In the present section are shown the distributions of surface temperature, the heat flux ratio and the corresponding gradients in the combustion chamber wall along the chamber axis and their transient behavior during the hot run. As an example of the test results obtained in the present test campaign, in the following subsection, the 20-bar, OF $=2.6$ test case is shown in more details. 


\subsection{Temperature Distribution}

Surface thermocouples at different axial positions are installed for direct measurement of the local surface temperature inside the combustion chamber, whereas wall thermocouples at different distances $d$ from the hot gas wall are used to determine the temperature field in the chamber material. The axial and radial distribution of the thermocouples allows the determination of the heat flux variation along the axis and the reconstruction of the thermal field in the chamber wall, respectively.

Due to the transient nature of the problem, three time intervals are chosen for the evaluation of the test data. A representative time interval for the starting conditions $t_{0}$, a characteristic hot run time step $t_{1}$, and a shutdown condition time $t_{2}$. In Fig. 6, these time intervals are highlighted, where it can also be recognized a typical temperature rise and correlated pressure buildup during hot runs.

Figure 7 shows the temperature reading of the thermocouples positioned at $1 \mathrm{~mm}$ from the hot surface of the chamber along the chamber axis during firing. For the temperature vs. time trace, two main gradients could be typically recognized: a steeper increase in the first second after ignition, as the thermal wave travels through the chamber wall, and a smoother temperature increase during the remaining running time. Furthermore, it can be noticed that the slope of the wall temperature vs. time profiles decreases with time into the firing. The same trend could be identified in each temperature signal in the first and second chamber segments. Additionally, Fig. $7 b$ shows the readings of the thermocouples positioned on the external surface that present temperature not superior to $360 \mathrm{~K}$ during the complete hot run.

A nonconform behavior for higher mixture ratios (3.0 to 3.4 ) is exhibited from the Medtherm thermocouples positioned in the region next to the faceplate

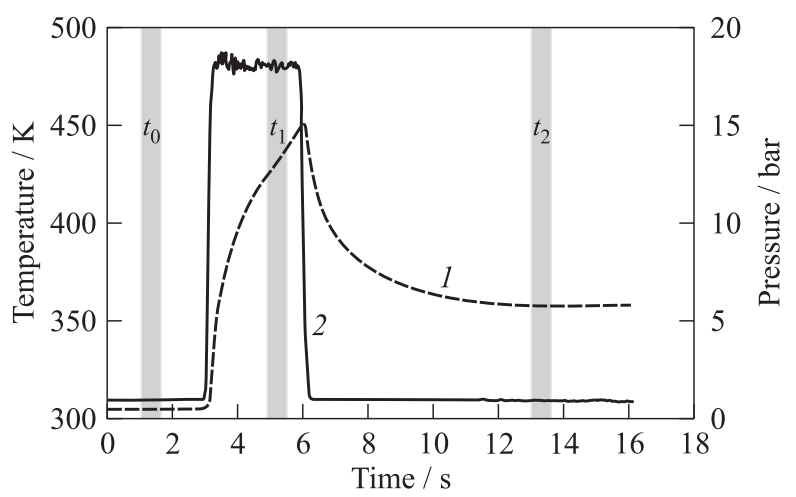

Figure 6 Temperature (1) and chamber pressure (2) buildup 


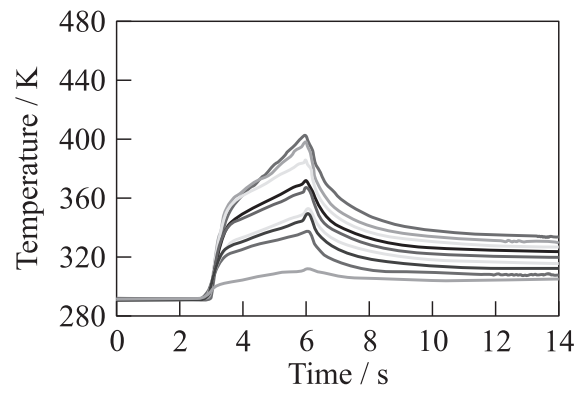

(a)

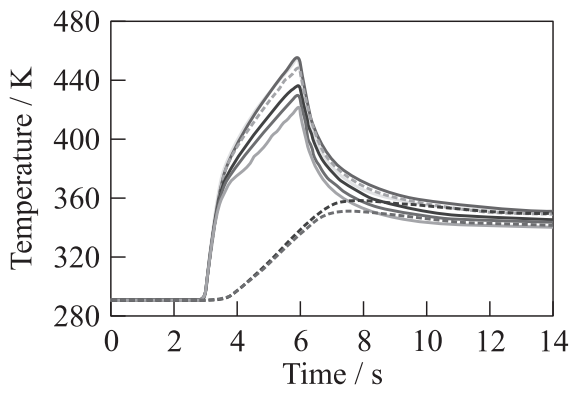

(b)

Figure 7 Thermocouple signals, distance $d_{1}$ : (a) 1st segment and (b) 2nd segment

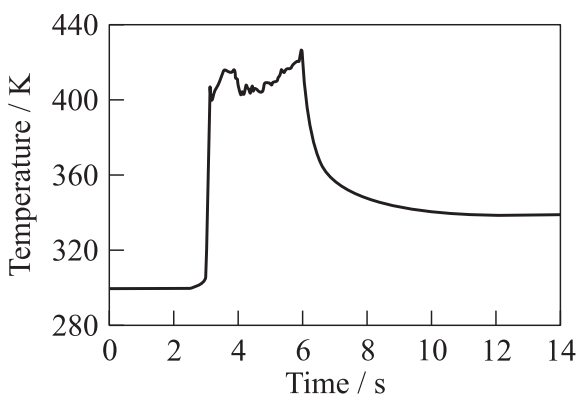

Figure 8 Medtherm temperature signal, $P_{\mathrm{cc}}=20$ bar, $\mathrm{OF}=3.4$, flush-mounted with the hot wall

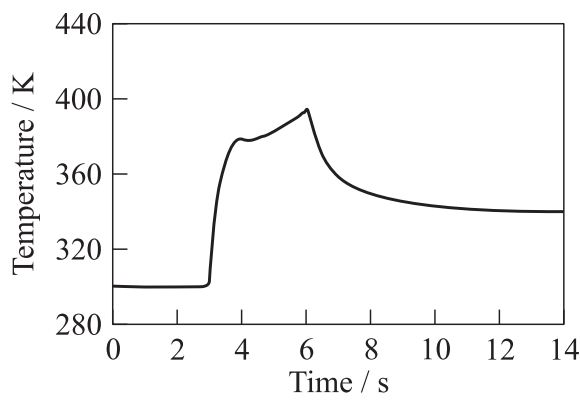

Figure 9 Temperature signal, $P_{\mathrm{cc}}$ $=20 \mathrm{bar}, \mathrm{OF}=3.4,2 \mathrm{~mm}$ from the hot wall

as shown in the example in Fig. 8. The temperature signal for this thermocouple increases steeper at the first $500 \mathrm{~ms}$ and then it decreases for a short period, before increasing with time until the end of the firing. This behavior was already observed at the Pennsylvania State University [2]. At that time, it was associated to a variation of the thermal contact between the thermocouple and the chamber. Since a similar temperature trend is also observed for the thermocouples signal at distance $d_{1}$ and even at $d_{2}$ from the hot gas side (Fig. 9), this hypothesis was abandoned for the current test setup. The first analysis shows that during the running time, the temperature of the wall never overcomes the condensation temperature of the water, which can be considered as one of the main reaction products. Moreover, the temperature peak has shown a sensitive response to $\mathrm{OF}$ changes and almost negligible variations with the combustion chamber pressure. While the mixture ratio approaches the stoichiometric value, the absolute and relative values of the peak increases, over the same time interval. Basic theoretical calculations (CEA2) for equilibrium chemical conditions show 


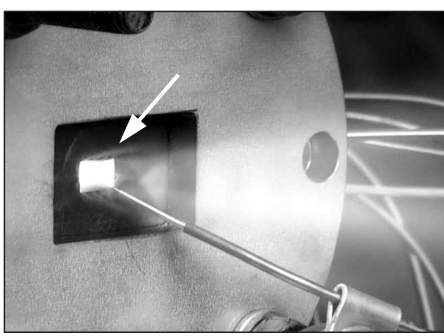

(a)

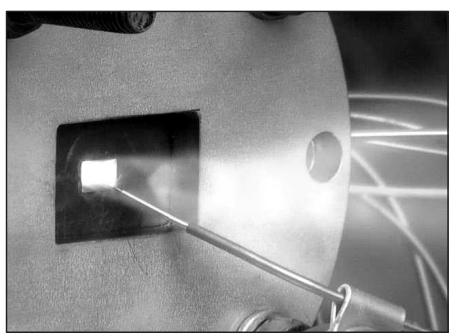

(b)

Figure 10 Exhaust plume at the start-up $(a)$ and during hot run at $t_{2}(b)$

for increasing mixture ratio an increase in availability in terms of molar mass of condensable means $\left(\mathrm{H}_{2} \mathrm{O}\right)$, while the molar mass of noncondensable products $\left(\mathrm{CO}, \mathrm{CO}_{2}, \ldots, \mathrm{H}_{2}\right)$ decreases. This leads to a higher likelihood of linking the temperature peak to the formation of a condensation film that seems stable enough to generate a thermal protective layer, at least for a short interval of time. Furthermore, a visual observation of the exhaust plume at the start-up indicates the presence of condensation, as seen in Fig. 10.

The formation of water may generate locally an increase in heat flux due to the enthalpy of vaporization and so the temperature peak. Previous studies [14] prove that the presence of a velocity field causes greater diffusion of the noncondensable gas at the interface into the bulk mixture and major diffusion of steam into the interface. This increases the steam mass fraction and the temperature at the interface in comparison with the case of lower velocities. It may explain the presence of only a short peak.

This justification is found to be not completely exhaustive and successive test activities are carried out. Test result shows in this case a clear correlation between the appearance of the temperature peak during the first part of the sequence and the operation of the torque igniter, mounted in the side wall of the chamber perpendicular to the main injector flame. Further study will investigate the phenomena in more details, analyzing the influence of igniter power, sequencing and positioning on the main flame [15].

Due to combustion, the temperature increases continously along the chamber axis till the accomplishment of the reaction processes. This statement is representative, especially for a heat sink hardware where the heat sink of the cooling system is not influency the behavior of the hot gas boundary layer. The temperature distribution along the chamber axis $(d T / d x)$ is shown in Fig. 11a for the complete set of thermocouples in the first and second segments. The temperature signals have been calculated as a mean value over a 0.5 -second time interval, taken at $2 / 3$ of the total run time $\left(t_{1}\right)$, in order to minimize the influence of the start-up transient. The run time is defined as the time duration, while both $\mathrm{GCH}_{4}$ and $\mathrm{GOx}$ propellant valves are fully opened. 


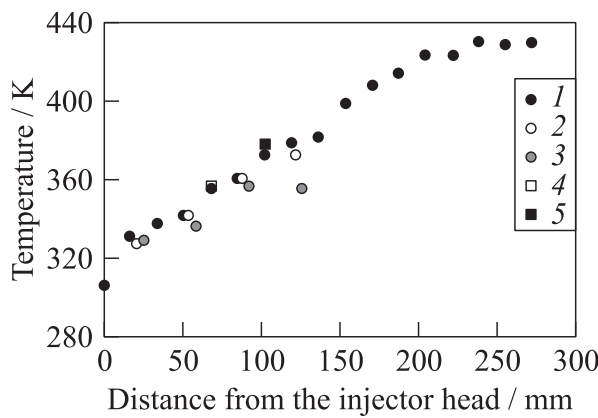

(a)

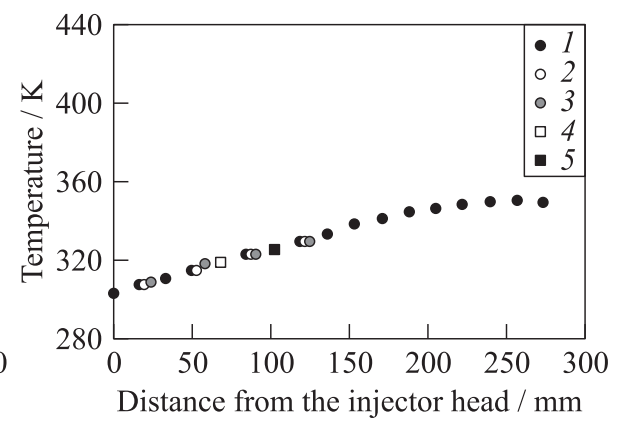

(b)

Figure 11 Temperature distributions along the chamber axis at time $t_{1}(a)$ and $t_{2}(b): 1-\mathrm{TCxUx} 1 ; 2-\mathrm{TCxUx} 2 ; 3-\mathrm{TCxUx} 3 ; 4-\mathrm{TCLD} 41 ;$ and $5-$ TCLD61

The curve presents a constant increase along the chamber axis till $x$ $=225 \mathrm{~mm}$ (where $x=0$ is the face plate position) and a short plateau can be identified in the last section close to the nozzle as indication of the end of combustion.

Figure $11 b$ presents the temperature readings of the thermocouples averaged over the time interval $t_{2}$, when the thermal equilibrium is reached after shutdown. The smooth profile, typically expected at the end of combustion, proves accuracy and correct positioning of the instrumentation and provides information for code validations. Generally, it has to be considered that throughout the whole test, the temperature distribution leads to a longitudinal heat transfer from the hotter downstream section of the chamber towards the faceplate, where the temperatures are lower.

\subsection{Heat Flux}

The characteristics of an injector element are mainly defined by the heat flux distribution on the hot wall along the combustion chamber axis. Due to the capacitive design of the hardware, heat fluxes can only be calculated from wall temperature measurements. Additionally, the limited test duration leads to nonstationary temperature signals. Measuring transient temperatures with sufficient accuracy for heat flux determination has been found to be challenging due to a significant sensitivity to the response time of the thermocouples.

For the present investigation, a simple one-dimensional (1D) approach cannot be used. Due to the rectangular cross section of the combustion chamber, the temperature gradient is not significant for only one coordinate direction and it is necessary to account for multidimensional effects. Thermal and geometrical conditions identify two relevant symmetry planes for the pro- 
posed geometry. Lines of symmetry are considered adiabatic, in the sense that there can be no heat transfer in a direction perpendicular to those lines. Therefore, for the current geometry, it is possible to consider a restricted portion of the geometry and analyze one-fourth of the complete configuration as shown in Fig. 12.

At the time interval $t_{1}$, the temperature distribution is fully established in the solid. Therefore,

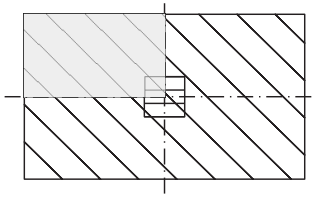

Figure 12 Control volume for heat flux calculations with the assumption of a constant heat flux on the hot gas side, the temperature may be considered to equally change at any point of the control volume. This allows defining the heat transfer problem only by the heat capacity of the control volume since the observation of the temperature traces over time implies a constant slope $d T / d t$ at time $t_{1}$. The energy balance, including the energy storage term, is defined by:

$$
\dot{E}_{\text {in }}-\dot{E}_{\text {out }}=\dot{E}_{\text {str }} \text {. }
$$

Then, it is possible to write it in terms of heat flux as

$$
\dot{q}_{\text {in }}-\dot{q}_{\text {out }}=\frac{m c}{A_{\mathrm{hw}}} \frac{\Delta T}{\Delta t} .
$$

The heat flux dispersed outside the chamber, due to natural convection, can be considered negligible and the properties, density, heat capacity, and conductivity of the copper are assumed constant. The temperature variation over time $(\Delta T / \Delta t)$ is calculated from the measured temperature signals during $t_{1}$. Equation (1) can be applied at each thermocouple position, since it is independent from the temperature level. Figure 13 shows the heat flux distribution along the chamber axis at $t_{1}$.

The heat flux increases from 1 (next to the faceplate) up to $9 \mathrm{MW} / \mathrm{m}^{2}$ (at the end of the combustion chamber). The values calculated using temperatures at different distances from the chamber wall seem to agree, and no big scattering around the trend line is featured. Also, in this case, as already highlighted in the temperature trend (see Fig. 11a), the signal presents a plateau in the last section upstream the nozzle, as indication of combustion end.

At time interval $t_{2}$, after the shutdown, the combustion chamber has reached a state, in which the temperature profile orthogonal to the chamber axis is equalized. From the longitudinal temperature profile previously presented in Fig. $11 b$, it is possible to calculate the average accumulated heat during the entire firing time. The values of the starting and final temperatures can be determined at time intervals $t_{0}$ and $t_{2}$.

The accumulated heat is defined by:

$$
Q=m c\left[T\left(t_{2}\right)-T\left(t_{0}\right)\right] .
$$




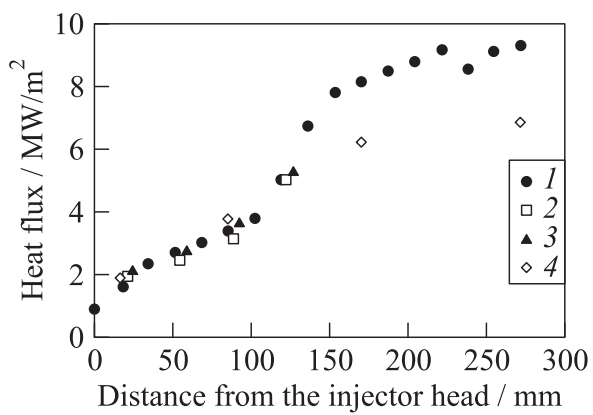

Figure 13 Heat flux distribution along the chamber axis at time $t_{1}: 1-d$ $=1 \mathrm{~mm} ; 2-2 ; 3-d=3 \mathrm{~mm}$; and 4 - surface

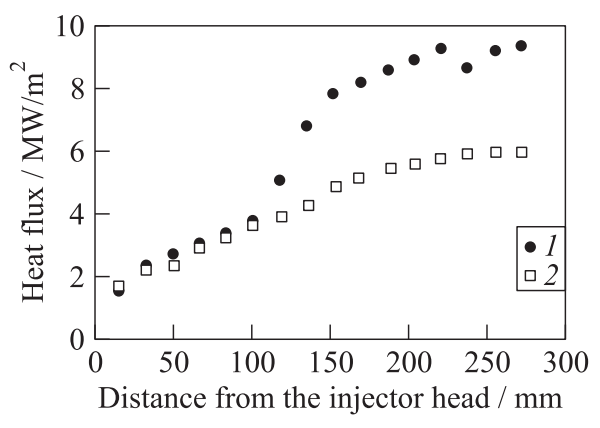

Figure 14 Heat flux distribution calculated by the accumulate heat along the chamber axis: $1-d=1 \mathrm{~mm}$ and $2-$ accumulated heat flux

The accumulated heat can be then correlated to the heat flux during burn time at each measurement position in order to be able to compare it with the previous method:

$$
\dot{q}=C_{1} \frac{\left[T\left(t_{2}\right)-T\left(t_{0}\right)\right]}{\Delta t_{\text {burn }}}
$$

where

$$
C_{1}=\frac{b h-a^{2}}{4 a} \rho c_{v}=0.2915\left[\mathrm{MJ} /\left(\mathrm{m}^{2} \mathrm{~K}\right)\right] .
$$

Since $C_{1}$ is a constant based only on geometry and material properties, the averaged value of the heat flux can be evaluated, knowing the temperature increase. The results obtained are shown in Fig. 14. It can be observed that, even if in the same order of magnitude, the values, calculated from the accumulated heat, suffer from the influence of heat losses to the environment and heat transfer in longitudinal direction to the components (i. e., manifolds and feed lines) in contact with the chamber segments.

A detailed analysis of the test data is performed using the described procedures. Figures 15 and 16 show a comparison of the heat flux along the chamber axis at time interval $t_{1}$ for different chamber pressures and different mixture ratios. In both cases, the characteristic of the heat release is not significantly shifted along the chamber axis. Due to the small changes in terms of velocity ratio and impulse ratio at the injection, no significant impact can be recognized between different operating conditions in the terms of mixing processes. The phenomena dominating the heat flux release is instead the combustion itself, as highlighted from the increase in steepness and absolute value of the heat flux profile with increasing pressure in the combustion chamber. To confirm repeatability of the test results, each operating point is performed at least two times. 

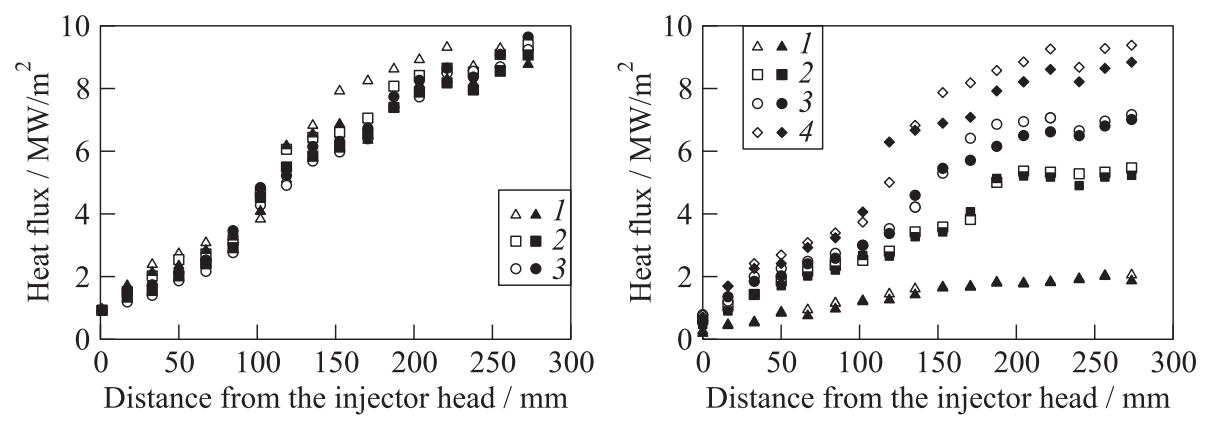

Figure 15 Heat flux distribution along Figure 16 Heat flux distribution along the chamber axis, $P_{\mathrm{cc}}=20 \mathrm{bar}$, at $t_{1}: 1$ - the chamber axis, $\mathrm{OF}=2.6$, at $t_{1}: 1-$ $\mathrm{OF}=2.6 ; 2-3 ;$ and $3-\mathrm{OF}=3.4 \quad P_{\mathrm{cc}}=5$ bar; $2-10 ; 3-15 ;$ and $4-$ $P_{\mathrm{cc}}=20$ bar

Test repetitions for different load points are included in the figures and present good agreement.

\subsection{Pressure Distribution and Discharge Coefficient of the Injector Element}

The design of the presented combustion chamber allows for the implementation of a high number of pressure sensors in the side walls. The nine pressure sensors are equally spaced with a distance of $34 \mathrm{~mm}$, double the spacing for the thermocouple measurements.

Due to the combustion process, the injected gas will be accelerated from injection velocity up to hot gas velocity $(320 \mathrm{~m} / \mathrm{s})$. Consequently, the wall pressure is expected to decrease along the chamber axis. Therefore, the end of the combustion process will be indicated by the flattening of the pressure gradient. Figures 17 and 18 show the static pressure distributions along the chamber axis for different values of chamber pressure and mixture ratios, normalized with the pressure at $x=272 \mathrm{~mm}$ (PC8), which is the last pressure sensor upstream the throat. The pressure signals are averaged over the same time interval forehead used for the temperature signals, $t_{1}$.

It could be identified a strong pressure gradient of up to the $4 \%$ of $P_{\mathrm{cc}}$, for every pressure value $P_{\mathrm{cc}}$ and OF. Similar results have been found in previous studies using $\mathrm{H}_{2} / \mathrm{LOx}$ propellant combination [16]. The drop in wall pressure at the face plate $(x=0)$ is linked to the presence of a recirculation zone triggered by the heat release and connected expansion directly after the injection point.

As already highlighted from the trend of the temperature signal along the chamber axis, the combustion processes seem to be accomplished shortly before An influence of the pressure level the nozzle. and of the mixture ratio on 


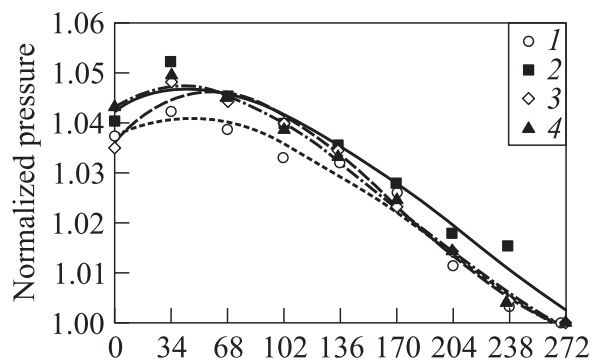

Distance from the injector head $/ \mathrm{mm}$

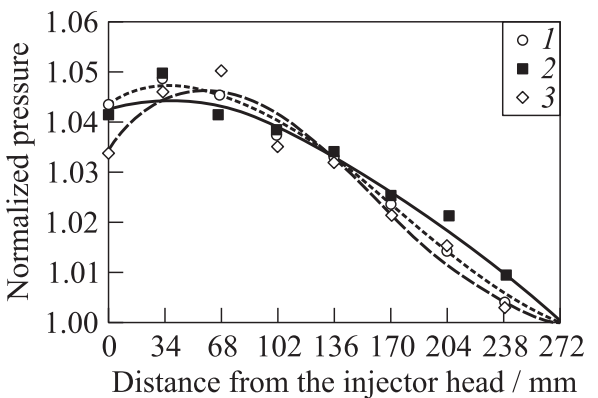

- Figure 18 Temperature along the axis (PC0...PC8), $\quad P_{\mathrm{cc}}=20$ bar: 1 $=5 \mathrm{bar} ; 2-10 ; 3-15 ;$ and $4-\mathrm{OF}=2.6 ; 2-3.0 ;$ and $3-\mathrm{OF}=3.4$ $P_{\mathrm{cc}}=20 \mathrm{bar}$

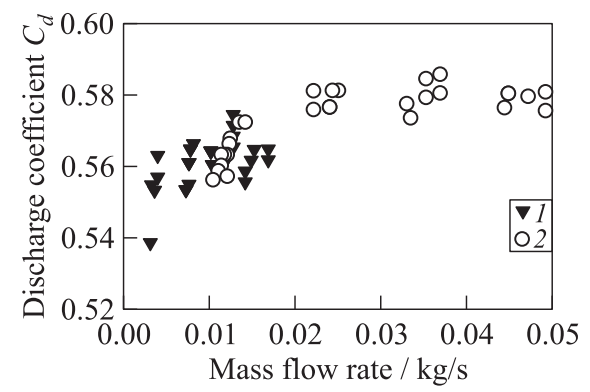

the extension of this area has not been observed during these investigations.

In order to fully characterize the behavior of the shear coaxial injector, $C_{d}$ values have been calculated over the different load points of the present test campaign and can be seen in Fig. 19. The calculations for the GOx use the inner cross section of the oxygen injection tube as reference area, while the ones for the methane post are based on the effective area of the $\mathrm{GCH}_{4}$ annular gap.

Figure $19 C_{d}$ values for different load points: $1-C_{d \mathrm{CH}_{4}}$; and $2-C_{d \mathrm{GOx}}$

No influence can be observed from the changes in combustion chamber pressures or mixture ratios. Typical values for the pressure losses at the design point for the oxygen tube are $25 \%$ of $P_{\mathrm{cc}}$ and of around $22 \%$ of $P_{\mathrm{cc}}$ for the methane side. The pressure drop is calculated from the manifold pressures upstream the injector element to the combustion chamber pressure PC0, the closest to the face plate.

\subsection{Thermtest Simulation}

The need for a reliable prediction of the thermal behavior of the institute's rocket combustion chambers has led to the development of the engineering tool Thermtest at TUM [10]. Thermtest allows the simulation of steady as well as transient thermal behavior of cooled or uncooled structures over a wide scope of chamber materials and cooling fluids. While the heat conduction inside the 
chamber material is solved by a three-dimensional finite difference method, the convective heat transfer is implemented by empirical Nusselt correlations. The advantage of this approach is a satisfying accuracy maintaining a reasonably fast simulation of the conjugate heat transfer from the hot gas into the cooling fluid.

Thermtest utilizes 1D hot gas properties acquired from the NASA computer program CEA2 of Sanford Gordon and Bonnie McBride [13]. The temperature of the combustion gases and the ideal characteristic velocity are calculated using the built-in rocket problem. The "injector" level used in this problem case is implied to be right at the injector face plate and "combustion end" at the end of the tubular combustion chamber section. The evolution of temperature caused by reaction kinetics and atomization processes is generally neglected as it is not taken into account in CEA2. The fluid properties needed for heat transfer calculations near the hot chamber wall are calculated assuming an equilibrium composition frozen reactions temperature-pressure problem. The convective heat transfer from the hot gas to the inner wall, as well as from the wall to the coolant is modeled using different problem specific Nusselt correlations. Thereby, the hot wall heat transfer coefficient is usually calculated from a modified formulation proposed by Sinyarev $[17,18]$. In the past, Thermtest has been validated and adapted for the use of kerosene/oxygen as propellants in small single-element combustion chambers featuring swirl or double swirl coaxial injector elements. Information on Thermtest as well as a comparison with experimental data and calculations from commonly available computational fluid dynamics (CFD) code has been published $[19,20]$.

For the implementation of the propellant combination methane/oxygen, the new injector characteristic, and chamber design, efforts have to be done. To account for the multidimensional behavior characterizing the rectangular cross section of the subscale combustion chamber presented, the code has already been adapted and upgraded, instead the correct implementation of the heat transfer for the new propellant combination has to be validated. Pressure signals, mass flow rates, or mixture ratio values, fed directly from the reading of the test data, are the input used for the simulations. Inspired by work of [21], a correction function for the heat load characteristic of generic coaxial injector elements has been applied in order to take the injector mixing behavior into account. The complete correlation is presented in

$$
\dot{q}_{w, \text { corr }}=\dot{q}_{w}\left(0.2+0.8 \tanh \left(\frac{x}{l_{\max }} \pi\right)\right) .
$$

Beside the "fixed" initial heat transfer ("0.2") and the axial coordinate $x$, the maximum combustion length $l_{\max }$ is the only parameter. The value of $l_{\max }$ has been arbitrary chosen equal to combustion length, since the experimental results show that the accomplishment of the combustion process happens on the complete chamber length. Preliminary simulation results obtained are shown in Fig. $20 a$ where it is possible to recognize the characteristic behavior for a heat- 


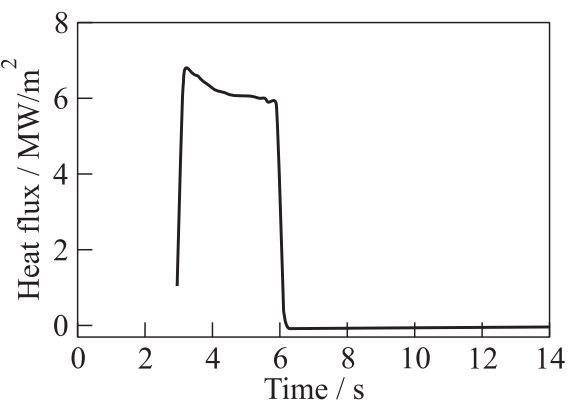

(a)

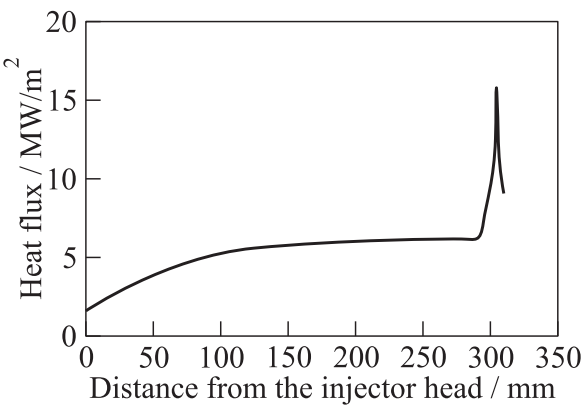

(b)

Figure 20 Heat flux vs. time $(a)$ and heat flux profile along chamber axis $(b)$ in Thermtest

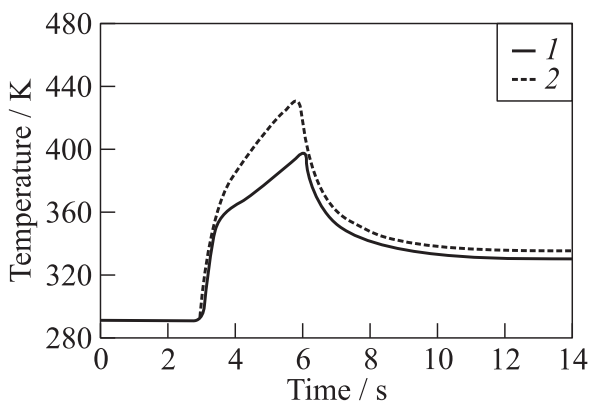

(a)

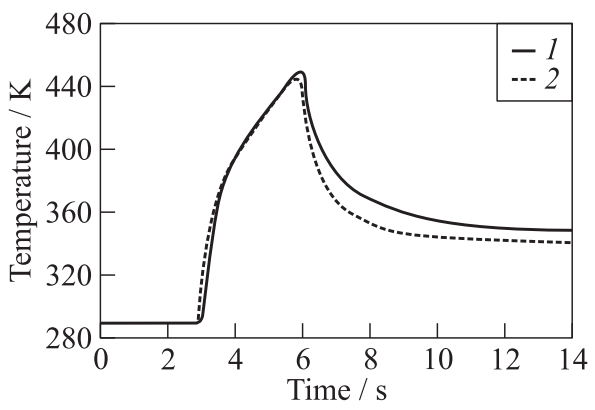

(b)

Figure 21 Temperature vs. time in the first $(a)$ and second $(b)$ segments, $t_{1}: 1-$ experimental data; and 2 - Thermtest simulation

sink rocket: the heat flux decreases during the hot run due to the structural temperature increase.

Heat flux profile along the chamber axis is plotted in Fig. $20 b$.

Temperature signals (Fig. 21) show an agreement with the experimental data in terms of absolute values and trend, especially in the second segment of the combustion chamber, while in the first segment, a greater disagreement between the simulated data and the measured ones is present.

\section{CONCLUDING REMARKS}

In the context of the national research program Transregio SFB/TR 40, two multiinjector combustion chambers are designed for $\mathrm{GOx}$ and $\mathrm{GCH}_{4}$ propellants research purposes. Before the manufacturing and testing of the aforementioned hardware, a single-element combustion chamber has been designed and tested 
in order to characterize the injector and to validate the in-house design tool Thermtest. Detailed wall temperature measurements and derived heat flux data sets have been obtained for $\mathrm{GOx} / \mathrm{GCH}_{4}$ single-element shear coaxial injector in a subscale combustion chamber over a range of pressure (5 to 20 bar) and mixture ratio (2.6 to 4.0) conditions. These data sets are valuable for both injector design and code validation. Due to the important multidimensional effects characterizing the geometry of the chamber and the transient nature of the hardware, specific methods for heat flux calculations have been considered. Temperature, heat flux as well as pressure traces show that the combustion process is accomplished towards the end of the chamber. The same trend was observed for all investigated load points. Preliminary simulations, conducted with Thermtest, show good agreement with the experimental results. An optimization, according to the test data, of the heat transfer model in order to match the injector characteristics is ongoing at TUM. The observed condensation phenomenon will be addressed in more detail in future test campaigns.

\section{ACKNOWLEDGMENTS}

Financial support has been provided by German Research Foundation (Deutsche Forschungsgemeinschaft - DFG) in the framework of the Sonderforschungsbereich Transergio 40. Furthermore, part of the present work has been supported by students of the TUM, namely, Christian Franzmann and Arne Lampmann. Furthermore, the authors like to thank Christian Bauer for the support provided.

\section{REFERENCES}

1. Preclik, D., G. Hagemann, O. Knab, C. Mäding, and D. Haesler. 2005. LOx/hydrocarbons preparatory thrust chamber technology activities in Germany. AIAA Paper No. 2005-4555.

2. Locke, J. M., P. Sibtosh, and R. D. Woodward. 2007. Chamber wall heat flux measurements for a $\mathrm{LOx} / \mathrm{CH}_{4}$ uni-element rocket. AIAA Paper No. 2007-5547.

3. Kalmykov, G. P., and S. V. Mosslov. 2000. Liquid rocket engines working on oxygen methane for space transportation system of the XXI century. IAF-00-5.2.10.

4. Liang, K., B. Yang, and Z. Zhang. 1998. Investigation of heat transfer and coking characteristics of hydrocarbon fuels. J. Propul. Power 14(5):789-796. doi: $10.2514 / 2.5342$.

5. Burkhardt, H., M. Sippel, A. Herbertz, and J. Klevanski. 2004. Kerosene vs. methane: A propellant tradeoff for reusable liquid booster stages. J. Spacecraft Rockets 41(5):762-769. doi: 10.2514/1.2672.

6. Götz, A., C. Mäding, L. Brummer, and D. Haeseler. 2001. Application of non-toxic propellants for future advanced launcher vehicles. AIAA Paper No. 2001-3456. 
7. Vingert, L., M. Habiballah, and P. Vuillermoz. 2002. Upgrading of the Mascotte cryogenic test bench to the LOx/methane combustion studies. 4th Conference (International) on Launcher Technology "Space Launcher Liquid Propulsion." Liege: CNES.

8. Cuoco, F., B. Yang, and M. Oschwald. 2004. Experimental investigation of LOx/ $\mathrm{H}_{2}$ and $\mathrm{LOx} / \mathrm{CH}_{4}$ sprays and flames. 24th Symposium (International) on Space Technology and Science. Miyzaki. ITS 2004-a-04.

9. Fröhlich, A., M. Popp, G. Schmidt, and D. Thelmann. 1993. Heat transfer characteristics of $\mathrm{H}_{2} / \mathrm{O}_{2}$ combustion chambers. AIAA Paper No. 93-1826.

10. Kirchberger, C., G. Schlieben, and O. J. Haidn. 2012. Assessment of analytical models for film cooling in a hydrocarbon/GOx rocket combustion chamber. AIAA Paper No. 2012-3909.

11. Celano, M. P., S. Silvestri, G. Schlieben, C. Kirchberger, O. J. Haidn, and S. Menon. 2014. Numerical and experimental investigation for a $\mathrm{GOx}_{\mathrm{x}}-\mathrm{GCH}_{4}$ shear-coaxial injector element. Köln: Space Propulsion.

12. Suslov, D., A. Woschnak, J. Sender, and M. Oschwald. 2003. Test specimen design and measurement technique for investigation of heat transfer processes in cooling channels of rocket engines under real thermal conditions. AIAA Paper No. 20034613.

13. Gordon, S., and B. McBride. 1994. Computer program for calculation of complex chemical equilibrium compositions and applications. NASA Reference Publication 1311.

14. Hanchoon, L., and K. Moohwan. 2001. The effect of non-condesable gas on direct contact condensation of steam/air mixture. J. Korean Nuclear Soc. 33(6):585-595.

15. Silvestri, S., M.P. Celano, G. Schlieben, C. Kirchberger, and O. J. Haidn. 2014. Characterization of a $\mathrm{GOx}-\mathrm{GCH}_{4}$ single element combustion chamber. Köln: Space Propulsion.

16. Suslov, D. I., R. Arnold, and O. J. Haidn. 2009. Investigation of two-dimensional thermal loads in the region near the injection head of a high pressure subscale combustion chamber. 47th AIAA Aerospace Sciences Meeting Including the New Horions Forum and Aerospace Exposiotion. Orlando, Florida.

17. Sinyarev, G. B., and M. V. Dobrovol'skiy. 1955. Zhidkostnye raketnye dvigateli. Teoriya i proektirovanie [Liquid rocket engines. Theory and design]. Moscow: Oborongiz. 499 p.

18. Schmidt, G. 1999. Technik der Flüssigkeits-Raketentriebwerke. Munich: DaimlerChrysler Aerospace.

19. Kirchberger, C., R. Wagner, H.-P. Kau, S. Soller, P. Martin, M. Bouchez, and C. Bonzom. 2008. Prediction and analysis of heat transfer in small rocket chambers. AIAA Paper No. 2008-1260.

20. Bouchez, M., E. Dufour, F. Cheuret, J. Steelant, P. Grenard, J. Redford, N. Sandham, A. Passaro, D. Baccarella, M. Dalenbring, and J. Smith. 2008. Material-aerothermal interaction computations in the ATLLAS European programme. AIAA Paper No. 2008-4670.

21. Ponomarenko, A. 2014. RPA - tool of rocket propulsion analysis. Space Propulsion Conference. Cologne, Germany. 